\title{
Obituary
}

\section{Francis J White}

Neuropsychopharmacology (2008) 33, 460; doi: I0.1038/sj.npp. I 301583

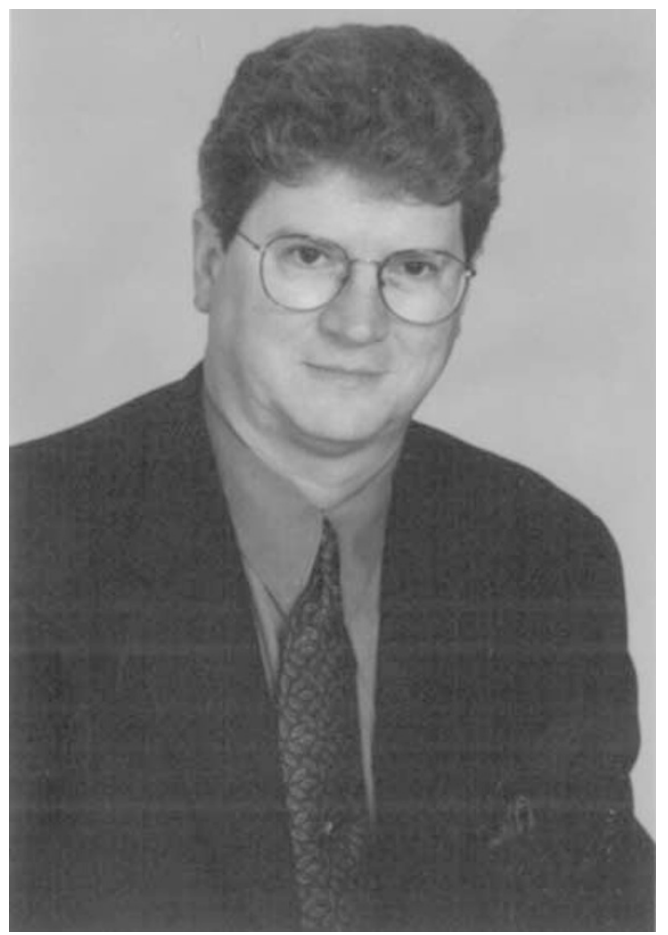

Surrounded by friends and family, Francis J White died on November 7, 2006 in a Chicago hospital. The untimely passing of Frank at 54 years old was a substantial loss to friends, colleagues, family, as well as the entire field of dopamine neurobiology. A native South Carolinian, Frank earned his PhD with Jim Appel, Kathy Cunningham, and Don Kuhn in 1981 at the University of South Carolina, studying the behavioral psychopharmacology of hallucinogens. After co-authoring 15 papers as a graduate student, Frank continued to distinguish himself when, in 1983, he and his postdoctoral mentor Rex Wang at St Louis University reported the disparate effect of typical and atypical antipsychotics on the spontaneous firing of A9 and A10 dopamine neurons, providing a potential explanation for their differential clinical effect on unwanted motor side effects. In 1984 Frank accepted a faculty position in Psychology at the University of Illinois Champaign Urbana and in 1987 he was recruited by Sam Gershon to the Lafayette Clinic and Department of Psychiatry at Wayne
State University in Detroit. Typical of his charisma, Frank convinced six graduate students to move to Detroit to join a nascent $\mathrm{PhD}$ training program in cellular and clinical neurobiology. Shortly thereafter, he and David Clark authored a probing review (over 600 citations) of the potential function of D1 and D2 receptors and Frank initiated studies on psychostimulant-induced plasticity of dopamine electrophysiology. After establishing himself as a leader in the neurobiology of addiction, in 1992 Frank, Xiu-Ti $\mathrm{Hu}$, and Marina Wolf were recruited to Rosalind Franklin University of Medicine and Science (formerly Finch University Chicago Medical School). Promoted to Chair of Pharmacology in 1998, Frank built a strong department focused on neuroscience research as well as graduate training while maintaining a highly productive individual research program. Frank's research endeavors were supported continuously by NIDA, including a prestigious MERIT award. He served as President of the Chicago chapter of the Society for Neuroscience, NIDA councilor for medications development, and senior editor for Neuroscience. Frank considered his acceptance into the College as a crowning achievement in his professional career.

Frank was a gregarious fellow with a passion for music, fine wine, baseball, golf, and gourmet cooking. Dinner with Frank was a memorable event, whether in DC, New Orleans, France, or Italy. Consonant with his long-standing commitment to the training and well-being of promising young neuroscientists, Frank was most delighted and proud of his two daughters Jessie and Lucy. In January 2007, Micky Marinelli, in conjunction with RFUMS, sponsored a moving memorial to Frank's life, including creation of a fund for neuroscience trainees; details are provided at http:// www.rosalindfranklin.edu/cms/Pharmacology/Marinelli/ Frank.htm. Besides his daughters, Frank is survived by his mother Delores, siblings Cheryl, Buck, and Mike as well as his former wife and colleague Marina Wolf. Frank touched an innumerable population and his presence is sorely missed.

Frank suffered during his final years and eventually he succumbed to the firm grip of addiction, ironically the disease that was the hallmark of his scientific career. The paradox between his personal and professional life is a testament to the power of addiction plasticity; more importantly, it serves as an ongoing incentive to discover the basis of that neuroadaptation and the ability to reverse it.

Matthew P Galloway

Psychiatry and Behavioral Neurosciences and Anesthesiology, Wayne State University School of Medicine, Detroit, MI, USA 